Peris Muñoz, Carlos.

Doctorando, Universidad Politécnica de Valencia, Facultad de Bellas Artes, grupo.

\title{
El trabajo fotográfico de Cy Twombly
}

\section{Cy Twombly's photographic work}

TIPO DE TRABAJO: Comunicación.

\author{
PALABRAS CLAVE
}

Fotografía, Pintura, Cy Twombly, Polaroid.

KEY WORDS

Photograpy, painting, Cy Twombly, Polaroid.

\section{RESUMEN}

La fotografía se encuentra en un estado de masificación incontrolado. Todo el mundo es fotógrafo. En el terreno de las artes plásticas, todo creador (ya sea pintor, escultor, grabador...) es paralelamente fotógrafo. Históricamente, encontramos precedentes de estas relaciones entre las diferentes disciplinas de las artes plásticas hasta crear un todo inseparable y, en la praxis del pintor, su relación con la fotografía se presenta de una manera directa y hermanada. En el caso de Cy Twombly, tanto su estética como su multidisciplinaria producción, muestran un camino en que la fotografía se adopta como posible vía de exploración o nervio de producción. Todo ello nos lleva a necesitar, como observadores, un móvil; el espectador necesita saber por qué el modus operandi de un artesano de la materia pintura, intercede e interactúa con tal máquina, es decir, qué utiliza, qué extrae, cuál es el drenaje obtenido de tal acción. En esta comunicación se presentan y analizan los principios básicos del trabajo fotográfico de Cy Twombly.

\section{ABSTRACT}

Photography is in a state of uncontrolled massification; everyone is a photographer. In the field of plastic arts, nowadays every creator (be it a painter, sculptor, engraver...) is, at the same time, a photographer. Historically, we find precedents of these relationships between the different disciplines of the plastic arts to create an inseparable whole and, in the praxis of the painter, this relationship with photography is presented in a direct and twinned way. In the case of Cy Twombly, both its aesthetics and its multidisciplinary production, show a path in which photography is adopted as a possible route of exploration or production nerve. This leads us to need, as observers, a motive; the viewer needs to know why the modus operandi of an artisan of the pictorial matter intercedes and interacts with the photographic machine; what he uses, what he extracts, what is the drainage obtained from such action. This communication analyzes and presents the basic principles of Cy Twombly's photographic work.

\section{INTRODUCCIÓN}

La reconocida figura de Cy Twombly ha sido analizada y comentada ampliamente, tanto durante su carrera artística como póstumamente. Desde las más amplias disertaciones formales, hasta los textos más breves y poéticos; tratando tanto lo plástico y matérico en su obra, como lo más conceptual y subyacente. De toda esta compilación de textos para catálogos, libros y publicaciones, podemos considerar, desde un primer recuento, que una gran mayoría de ellos tratan, sobre todo, su obra plástica (en concreto pinturas, esculturas y dibujos). De entre toda esta suma (unas 1028 publicaciones según la Fondazione Nicola Del Roscio), menos de un $2 \%$ trata su obra fotográfica. Y de este porcentaje, solo unas 10 de estas publicaciones tratan exclusivamente sobre su fotografía. Todo esto sin mencionar la existencia, desde hace ya bastantes años, de varios números formales de catálogos razonados a cerca de 
sus pinturas, dibujos y esculturas, pero solo unos volúmenes que reúnen las fotografías publicadas por Twombly de una manera no cronológica ni razonada ${ }^{1}$.

Si bien parece que, a primera vista y basándonos en las cifras anteriores, atendemos, quizá, a una dedicación aparentemente marginal en el artista, la obra fotográfica de Cy Twombly casi puede presentarse como un nexo ineludible entre todo su modus operandi como creador. No es de extrañar que mucho tiempo después de su primera publicación en 1993, las fotografías de Twombly vayan ocupando un espacio mayor entre sus exposiciones y publicaciones. Ya no solamente el creciente número de muestras y textos dedicados exclusivamente a su trabajo fotográfico avalan la importancia que se le está dando en los últimos años a este tema, sino también podemos apreciar esta valoración en los resultados de las subastas, dónde vemos que su cotización está al alza, así como también la inclusión de estas fotografías en las últimas exposiciones retrospectivas (Storsve, 2016).

En las siguientes líneas se analiza y expone de manera cronológica la relación de esta práctica fotográfica con el resto de su obra plástica, así como la relación artística de Cy Twombly con Robert Rauschenberg y los resultados derivados de ella. También nos acercaremos a los métodos y máquinas utilizados, con el fin de establecer unos parámetros que definan las intenciones del autor.

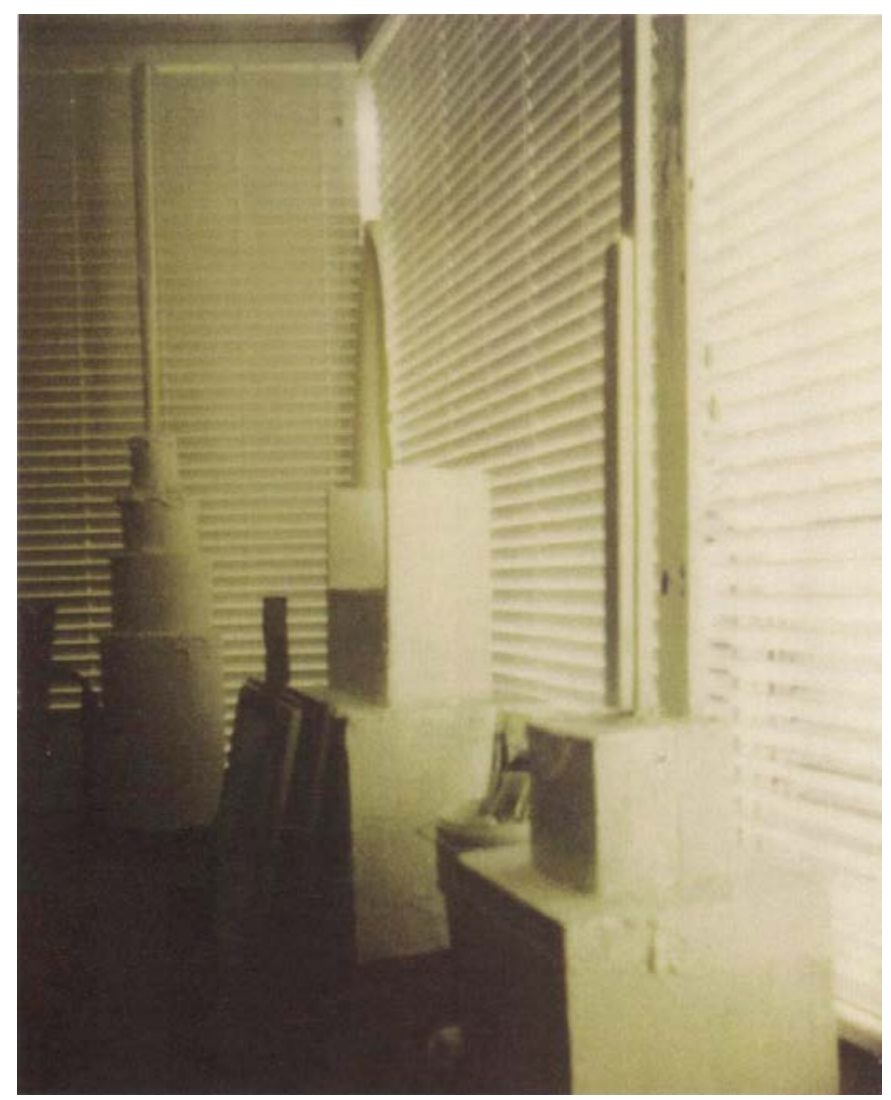

Figura 1 “Studio Lexington”, Cy Twombly, 2002. Fuente: Cy Twombly, photographs 1951-2007. „@Cy Twombly Foundation

\footnotetext{
${ }^{1}$ Sí cabe señalar que, puesto que estos catálogos fueron realizados cuando Cy Twombly vivía, fueron supervisados por el artista; la colocación de las imágenes, orden y parte de la maquetación, así como el diseño de la portada fueron, decisiones propias de Twombly; luego, podemos deducir que dedicaba una atención especial y detallada al respecto de las imágenes y fotografías.
} 


\section{METODOLOGÍA}

Esta comunicación, así como la investigación en la que se basa, tiene en la Cy Twombly Foundation y la Fondazione Nicola Del Roscio, y en el acceso su material de archivo en el que estamos trabajando, la principal fuente de consulta. Esto supone el contacto directo con material fotográfico original, archivo, biblioteca y objetos personales de Cy Twombly, así como relación y conversación directa, ya no solamente a nivel profesional, sino también personal y de camaradería con su director: el Sr. Nicola Del Roscio, el cuál fue durante la mayor parte de la carrera artística de Cy Twombly, editor, ayudante, compañero de viajes y amigo. Por otro lado, además de una estancia de estudios en el extranjero de seis meses en los archivos de las fundaciones, se ha estado trabajando en labores de archivo, catalogación y conservación contratado por la Cy Twombly Foundation, en su sede de Gaeta; esto ha aportado mucha más cercanía y análisis del material con el que trabajamos aquí y exponemos en esta comunicación.

\section{DESARROLLO}

A pesar de su principal interés por el medio pictórico desde sus primeras obras, el desarrollo artístico de Twombly nunca ha estado delimitado o acotado por un medio o un proceso específico. Las imágenes que tenemos de primeros trabajos de Cy Twombly refieren a composiciones pictóricas cercanas al Expresionismo Alemán o pequeñas construcciones tridimensionales inclinadas hacia una estética Dada, movimientos en los que Cy Twombly mostraba interés en la época (Storsve, 2016). En aquel momento, su amplio conocimiento e impulso cognitivo sobre el arte y, en especial la pintura, llevan al joven Twombly a matricularse en la Escuela del Museo de Boston. Permanece allí hasta la apertura del nuevo departamento de arte de la Washington and Lee University de Lexington en 1949, dónde solicitará la beca de la Liga de Estudiantes de Arte de Nueva York (Art Students League of New York). Allí sigue en contacto con la pintura de los grandes vanguardistas de la época como Jackson Pollock, Mark Rothko o Robert Motherwell e inicia su gran amistad con Robert Rauschenberg.

En cuanto a producción o creación fotográfica se refiere, no encontramos imágenes que puedan atribuirse directamente a Twombly hasta los inicios de los años 50 (Molesworth, 2015), durante su estancia en los cursos de verano e invierno del conocidísimo Black Mountain College, en Carolina del Norte (1951-1952).

Como era común en los conocimientos impartidos en la institución artística, tampoco aquí Cy Twombly limitaba su desarrollo artístico a un medio o procedimiento fijo. En la escuela, los asistentes (o participantes, ya que no se trataba de una escuela como tal dónde existía una jerarquía rígida y una diferenciación entre el profesorado y los alumnos) compartían e intercambiaban conocimiento entre los diferentes medios y procesos creativos (Molesworth, 2015). Así pues, cualquiera que asistiese a las experiencias de intercambio creativo del Black Mountain College, entraba en una dinámica de relación interdisciplinar; desde los procesos más clásicos como la pintura o la escultura, a otros más innovadores para la época como el sonido o el teatro, los cuales dieron paso a movimientos destacados y más delimitados estéticamente, como la performance o el arte sonoro.

Dentro de este clima de intercambio y relación interdisciplinar (muy influenciado por el ambiente de la época próximo a lo hipee), Twombly desarrolla, entre otros procesos, una potente inclinación hacia la fotografía. Estudia fotografía de la mano de Hazel Larsen Archer, compartiendo su experiencia con otros artistas como Robert Rauschenberg o Dorothea Rockburne:

"I first met Cy at Black Mountain College in the fall of 1950, when he and Rauschenberg were there together. They were both stunningly handsome. They were never students in the strict sense. They were there to grab free time to paint and to partake in the vast richness of that intellectual community.» (D. Rockburne, 2011, párr.2).

En estas primeras tomas realizadas por Twombly, a pesar de sus prácticas y de una vertiente de la fotografía propia del estudio y de la experimentación de la época, precisamente de una forma muy incisiva en el contexto del Black Mountain College, nos topamos ante fotografías de composiciones sencillas, con cámara estática y, en blanco y negro y con un contraste medio; en estas primeras imágenes ya vislumbramos a un Twombly fotógrafo-operador que no cesará de crear y propiciar esta clase de improntas en un futuro y a lo largo de su producción artística. El desenfoque, las composiciones en formato cuadrado, la sencillez, la precariedad y el aura de lo inestable son puntos clave en la asimilación de su fotografía, ya desde unos inicios incipientes. Encontramos en varias publicaciones que Twombly hacía uso de una cámara estenopeica (pinhole camera) para la toma de algunas de sus fotografías en este periodo. 

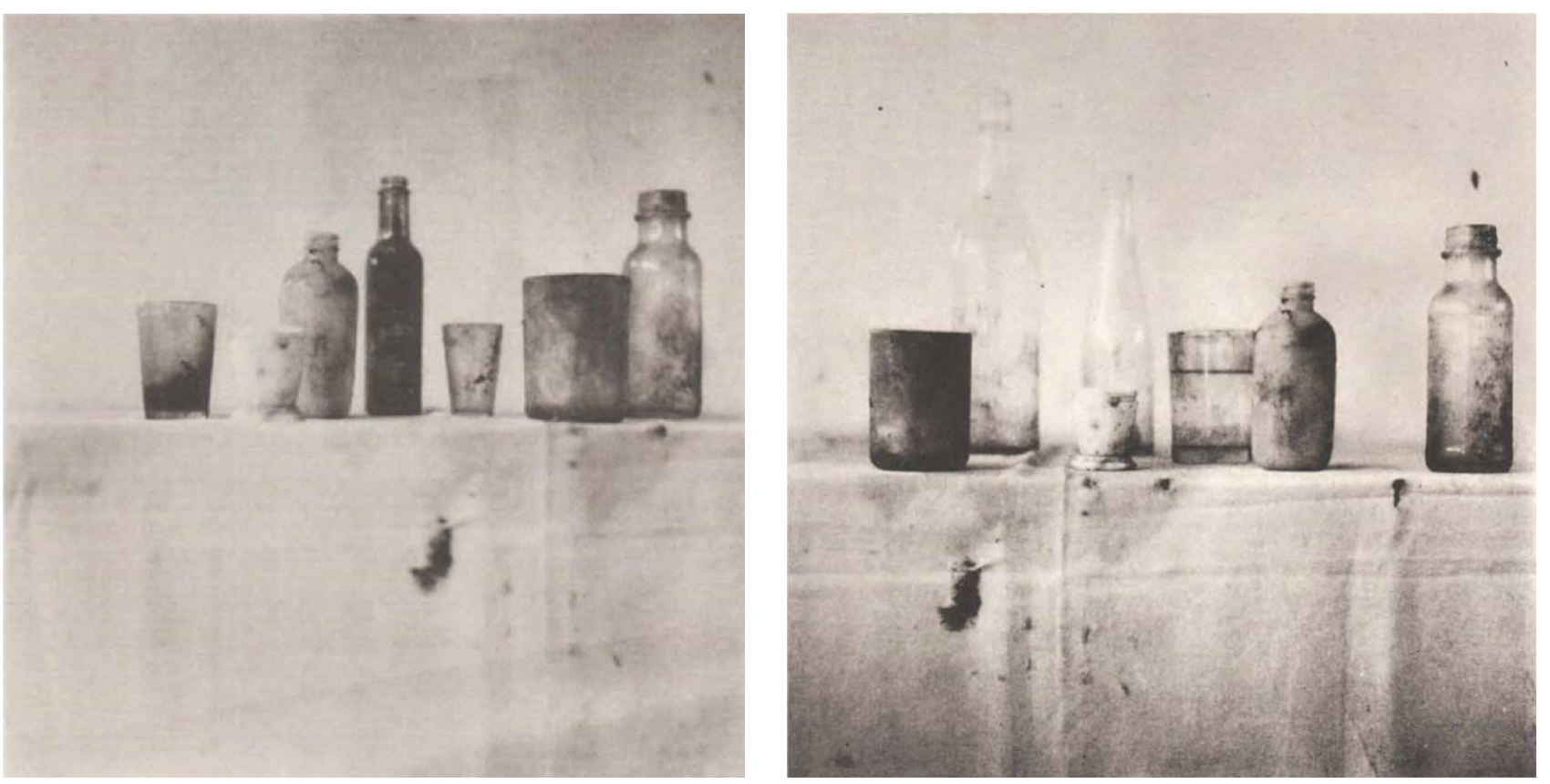

Figura 2. “Still life, Black Mountain College”, Cy Twombly, 1951. Fuente: Cy Twombly, photographs 1951-2007. CCy Twombly Foundation

También explorará otros tipos de tomas, así como otras cámaras y procesos, retratando a personajes de su entorno como Franz Kline o John Cage, o tomando encuadres del estudio de Willem de Kooning en el Black Mountain College, llevado de la mano de un inseparable Rauschenberg. Su relación con Robert Rauschenberg, el cual, aunque desde un punto de vista diferente al de Twombly, también fotografía impulsivamente todas esas formas que le rodean, lo lleva a agudizar esta práctica y a no despegarse del medio fotográfico durante un largo periodo de tiempo.

Tras adquirir una beca de viaje del Museo de Bellas Artes de Virginia, Twombly emprende, de nuevo junto a Rauschenberg, un viaje hacia Europa y el norte de África durante 1952 y 1953. El viaje, tras el desembarco en Palermo, comprendió la visita de varias ciudades de Italia (Nápoles, Roma, Florencia, Siena...) y la travesía desde Roma a Marruecos, dónde visitarían también varias ciudades del país Nord-africano, así como su vuelta en tren por España. Este periplo lleva a los dos jóvenes artistas a compartir conversaciones y temáticas junto a la cámara en una íntima relación artística afectiva y fecunda.

Esta unión entre los dos artistas conlleva a la contaminación estética recíproca y una colaboración íntima y cotidiana que no permite discernir qué fotografía disparó quién ${ }^{2}$. En su texto Camera Obscura, Nicholas Cullinan exponía:

"[Twombly and Rauschenberg] worked so closely together during these years that is sometimes difficult to distinguish who took that photograph [...] (Which we do know belonged - the Rolleiflex camera - to Rauschenberg)» (N. Cullinan, 2011, p.47).

El debate de la autoría de las fotografías está siempre presente entre Rauschenberg y Twombly entre las tomas de esta época. Realmente, es difícil distinguir quién ejecutó la fotografía, como bien apunta Cullinan, ya que los ideales estéticos y el trabajo en equipo durante aquel período no mostraba gran separación entre uno y otro artista ${ }^{3}$. Las disputas de la autoría nunca se han tomado

\footnotetext{
${ }^{2}$ Sí podemos asegurar que la cámara Rolleiflex pertenecía a Rauschenberg y era Twombly el que tomaba posesión momentánea de ella, ya fuese para retratar a Robert o para tomar sus propias composiciones, que luego repartirían una vez revelado el carrete - dato que asumimos, ya que parte de esos negativos estaban en posesión de Twombly y, tras su muerte, en posesión de la Fondazione Nicola del Roscio.

${ }^{3}$ Esta unión llegaba hasta tal punto que, tras últimas investigaciones, se ha probado que algún cuadro de Rauschenberg está pintado sobre los trazos de una pintura de Twombly de la época. Es un tema tratado por David White en el documental "Cy Dear", del cuál no podemos especificar una citación debido a que solo pudimos atender a su visualización privada en el MoMa de Nueva York durante el 25 de Abril de 2018 y no está publicado todavía. Para una futuras consultas: Cy Twombly Foundation. (2018). Cy Dear, [film] Roma: Good Day Films.
} 
muy en serio, ni por los artistas en vida, ni por las respectivas fundaciones actuales. Simplemente se identifica como un estado de amistad y como lo que realmente era: un intercambio entre artistas, donde a veces aparecía uno como el autor y otras el otro ${ }^{4}$.

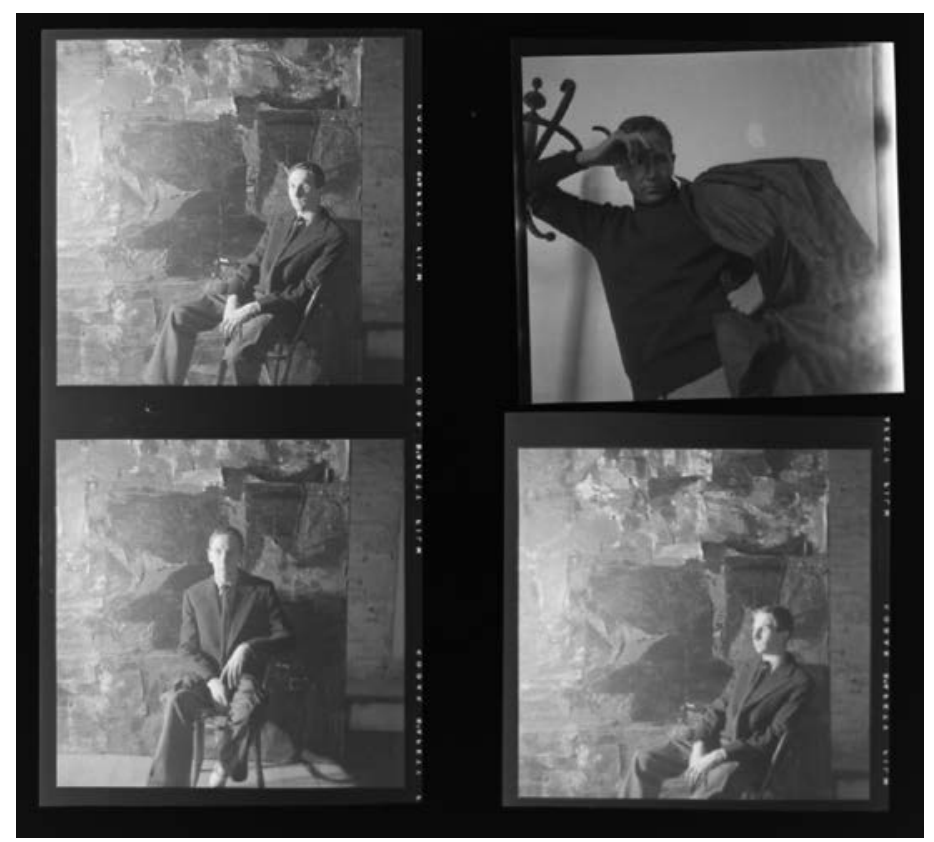

Figura 3. Varios negativos de tomas de Robert Rauschenberg realizadas por Twombly. Elaboración propia.

Tal y como Cullinan muestra en este fragmento, lo que sí que al menos tenemos claro, es que la máquina pertenecía a Rauschenberg. Esto nos deja como dato de interés ya no solo la íntima relación artística entre los dos protagonistas, sino también el añadir una nueva cámara al catálogo de máquinas utilizadas por Twombly. Por otro lado, la cita de Cullinan añade un punto de apoyo a la hipótesis de la necesidad de la toma por parte de Twombly y de cómo éste arrancaba de las manos de su acompañante la cámara para tomar ciertas fotografías. Tal vez, en estas fotografías podemos ver cómo Rauschenberg explora los límites más conceptuales y matéricos de la fotografía de una manera explosiva e inquieta, así como compositiva y casi pictórica, y apreciamos a un Twombly mucho más impulsivo y que casi podemos imaginar cómo decide robar la cámara de su compañero en un gesto caprichoso y lanzarse a captar ese momento, ya sea para retratarle o para plasmar esa impronta visual, que no es otra cosa más que, primordialmente, un estado mental y sensorial del momento ${ }^{5}$.

De vuela a los Estados Unidos a finales de la primavera de 1953, concretamente a la ciudad de Nueva York, Twombly trabaja un tiempo en el estudio de Robert Rauschenberg en el 61 Fullton Street. Además de desarrollar las primeras pinturas grises y algunas de sus esculturas más encaminadas en lo que será su estética escultórica predominante posterior (esculturas y pinturas que acaban, en su mayoría, destruidas - en algunos casos, re-construidas o re-pintadas correspondientemente), realiza algunas fotografías que recogen todos esos detalles. Entre dichas fotografías destacan las que posteriormente Twombly editó en las copias dry-print: «Robert Rauschenberg combine materials» y las fotografías de los conocidos como grey paintings, aunque también encontramos algunos posados de Rauschenberg junto a sus obras, partes del estudio o algún bodegón - si se pueden llamar así-.

\footnotetext{
${ }^{4}$ Nicola Del Roscio en entrevista con el autor: «Many photographs that Rauschenberg said were done by him they were done by Twombly. But, you know, he didn't contest anything, he just let it go.» (Del Roscio, 2 Junio 2017).

${ }^{5}$ Damos aquí, ya en estas jóvenes acciones fotográficas, con una de las constantes del uso de la cámara de Twombly a lo largo de toda su carrera artística; una de las hipótesis centrales, que comprende el trabajo fotográfico de Cy Twombly como una necesidad derivada del deseo de captura del estado mental y sensorial del momento, convirtiendo la cámara en la herramienta perfecta para este cometido estético; para la obtención de dicha imagen.
} 


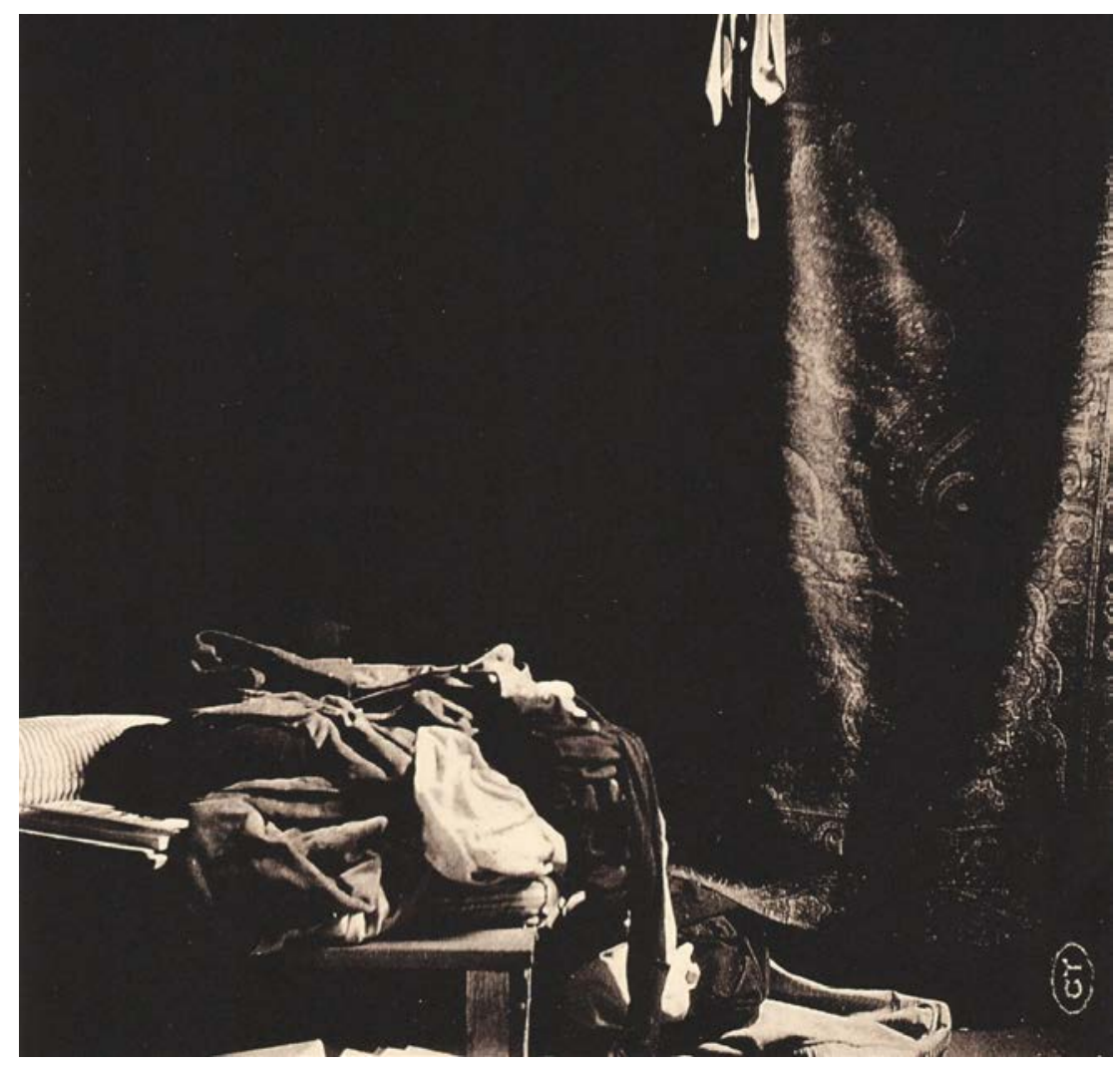

Figura 4. "Fulton St. Studio, NYC", Cy Twombly, 1954. Fuente: Cy Twombly, photographs 1951-2007. CCy Twombly Foundation

Años más tarde, tras su servicio militar en Washington DC y varias exposiciones de pinturas y dibujos, en 1957 deja Nueva York y viaja de nuevo a Italia. Durante estos años y hasta principios de los 70, Twombly lleva a cabo un corpus fotográfico que, de algún modo, podría ser más cercano a una práctica fotográfica más común, más ortodoxa en temáticas y procedimientos. Nos referimos aquí a fotografías de viajes y algunos retratos de familiares y personas cercanas. No encontramos fotografías publicadas que atiendan a una manera de hacer más próxima a lo ya realizado hasta el momento o a lo que vendrá posteriormente, a lo que hoy en día se conoce como la obra fotográfica de Cy Twombly. Sí se han podido encontrar, tras una búsqueda en los archivos de la fundación, algunas fotografías menores que contienen alguna traza de un lenguaje fotográfico más personal.

Lo que entendemos como lenguaje propio en la obra fotográfica de Cy Twombly, a modo de hipótesis, lo concebimos desde el momento justo en que Twombly decide coger la cámara hasta la firma y numeración de ejemplares reproducidos a partir de las matrices elegidas; un conjunto de características que vienen dados por la inmediatez de la captura de ese estado mental y físico del artista en relación con su entorno, en suma al gesto fotográfico y las decisiones matéricas posteriores en cuestiones de reproducción. Esto se traduce en imágenes veladas por estratos de grano y desenfoque, indiferentes al detalle anecdótico, que centran su ser en la captura de una esencialidad del objeto en su relación con la luz, la atmósfera y la presencia de lo circundante. Este lenguaje propio, como decíamos, no se dará hasta el lanzamiento al mercado de la cámara Polaroid SX-70 ${ }^{6}$, la cual permitía el disparo y el revelado de la fotografía en un solo paso y de manera más o menos instantánea.

La cámara Polaroid, tanto por su relativa instantaneidad como por su fácil uso y comprensión, aportará al artista un nuevo modo de entender y ejercer la fotografía. A diferencia de otros artistas que sí aportan una importancia al proceso y la elaboración del material para la realización de la foto, Twombly no necesitaba aportar tiempo a esa parte más técnica del proceso creativo; por el contrario,

${ }^{6}$ En 1972 en el estado de Florida y en 1973 a nivel nacional en los EEUU. Anteriormente, con la segunda generación de cámaras Polaroid, existían otros modelos en los que la instantaneidad de la película no era tal, sino que además de enfocar y disparar, una vez extraída manualmente la película, se debía pelar la fotografía separando el positivo del negativo una vez finalizado el proceso de revelado. 
podía suponer tedioso el tener que afrontar una parte técnica que lo desvinculara del estado de embriaguez estética. La producción de la obra, si lo podemos llamar de este modo (ya que, en un estado primigenio, estas fotografías no parecían pertenecer a tan alta categorización, sino que se generaban dentro de un continuo de espacio y acción creativa), tenía que venir de la mano del impulso y, a su vez, concretar en el momento preciso ${ }^{7}$. Así pues, el factor de simplicidad de la cámara, ligado al milagro de la aparición ${ }^{8}$ de la imagen fotográfica lleva a Twombly a la producción casi obsesiva de un material fotográfico que no se despegaba de todo un conjunto artístico, unificando, a nuestro juicio, pintura, escultura, dibujo y fotografía en un solo concepto: el proceso creativo.

Englobado en este concepto genérico y demasiado expansivo, hacemos referencia aquí, por un lado, a la atención prioritaria a ese proceso de la obra, tanto por parte del artista como por nuestra parte a un nivel de estudio y comprensión, pero por otro lado y de una forma más significativa, a toda esa variedad de medios (pintura, escultura, fotografía...) y su pertenencia a un solo y único lugar y acción creativos; un ámbito y espacio de trabajo conjunto, dónde se entremezclan los diferentes procesos, medios y producciones, sin distinción en su génesis. Este proceso creativo, sin un principio o un fin concretos, entendiendo la atemporalidad como parte de la propia obra producida; es decir, que no existe un inicio claro de cada producción, dando lugar al registro de instantáneas relacionadas con su hábito de trabajo y su vida cotidiana.

\footnotetext{
${ }^{7}$ Entendemos momento, ya no solo como el fragmento temporal, como un instante decisivo, sino también el espacio circundante en relación con el estado mental del artista.

${ }^{8}$ Nicola Del Roscio, acerca de por qué Twombly fotografiaba, en entrevista con el autor:

"Maybe he liked the "meraviglia della figura riprodotta istantaneamente", maybe... that marvellous thing that is Polaroid, you know? That expectation of a quick result.» (Del Roscio, Octubre 2016).
} 


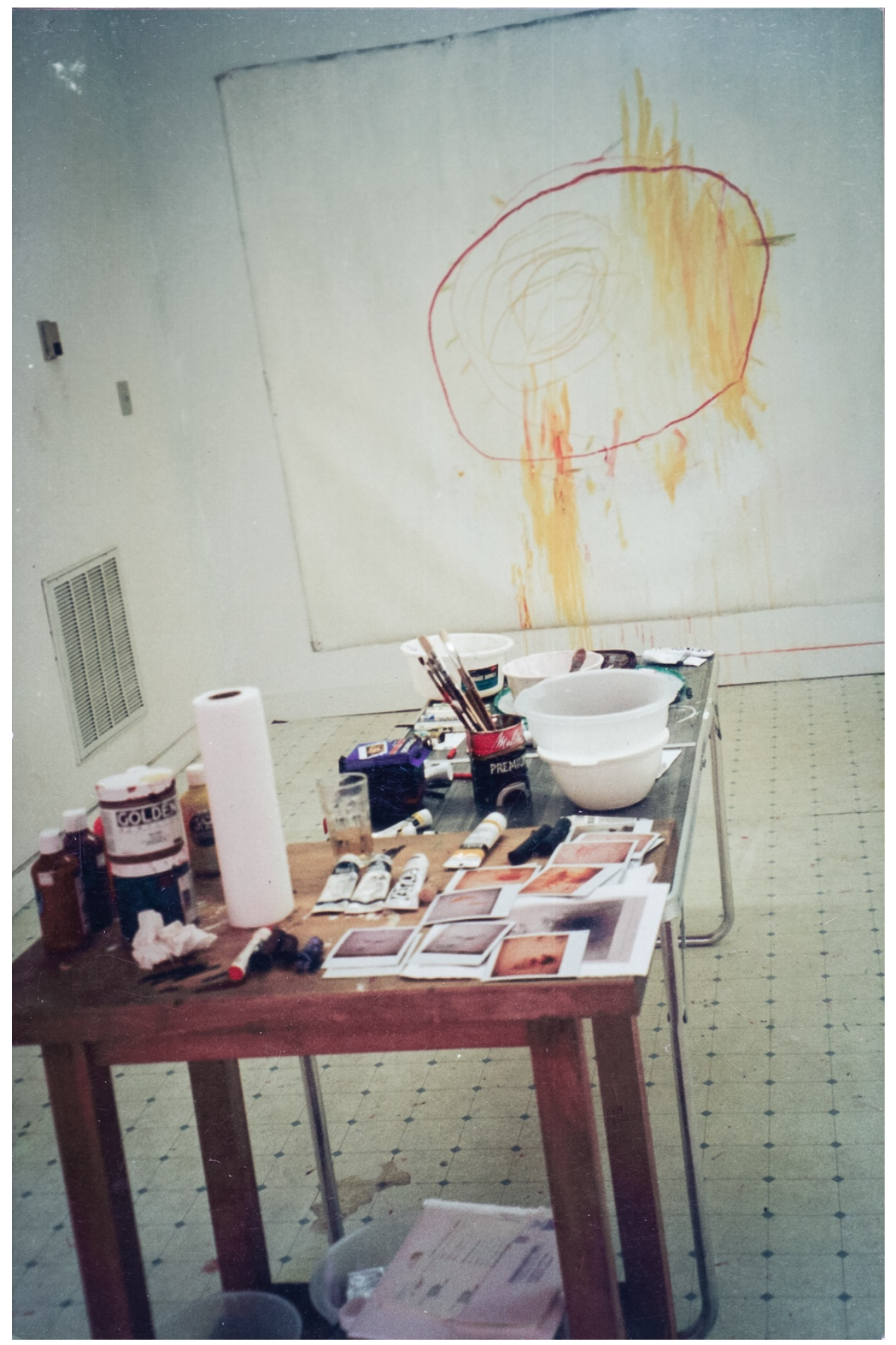

Figura 5. Estudio de Cy Twombly en Lexington, VA, dónde se puede ver uno de los cuadros de la serie "Coronation of Sestoris" y algunas Polaroid sobre la mesa. Fuente: Archivos Cy Twombly Foundation. (C)y Twombly Foundation

Abordando la temática fotográfica en Twombly, podemos decir que se caracteriza por la multiplicidad y la heterogeneidad, siempre rebosante de una sensibilidad particular a la hora de elegir lo fotografiado en cada instantánea. Ya puede considerarse una advertencia el adjetivo particular, ya que no se trata de un conjunto fotográfico sencillo de comprender o compilar en un mismo contenedor, pues lo dispar está presente en toda colección o selección de trabajos; ya hablemos desde el punto de vista de un aspecto estético y formal de la fotografía, el género o la elección de encuadre, siempre va a conllevar un arduo esfuerzo de comprensión y canalización de las palabras para una descripción certera e inteligible. Lo inefable es una de las presentes, primordialmente, en todo disparo de Cy Twombly, así como también nos encontramos con dicha característica en toda su producción artística. 


\section{CONCLUSIONES}

La compleja y heterogénea obra de Cy Twombly nos deja ante un panorama abrupto en cuanto a la descripción y análisis se refiere. Su producción fotográfica se encuentra en un terreno todavía más delicado e inexplorado el cual, a pesar de todo esfuerzo verbal, siempre acaba por esquivar toda descripción; el carácter personal, ambiguo y etéreo de su trabajo fotográfico nos deja, como investigadores, ante una pared de inefabilidad constante. A pesar de esta inestabilidad en la concreción de parámetros, podríamos llegar a afirmar que, además de tratarse de un placer estético perteneciente al terreno más íntimo de la producción artística personal, la fotografía para Twombly funcionaba, más allá de un bloc de esbozos o un registro fotográfico, como un encapsulador estético de estados mentales; una ayuda directa al recuerdo estético del momento y su entorno circundante, materializada en el objetual Polaroid.

\section{FUENTES REFERENCIALES}

Bachelard, G. (2012). La Poética del Espacio. México: Fondo de Cultura Económica.

Baqué, D. (2003). La Fotografía Plástica. Barcelona: Gustavo Gili.

Barthes, R. (1979). Non Multa Sed Multum. En Y. Lambert, Cy Twombly. Catalogue raisonné des oeuvres sur papier (Vols. IV (19731976)). Milan: Multhipla.

Barthes, R. (1989). La Cámara Lúcida: nota sobre la fotografía. Barcelona: Paidós.

Batchen, G. (2004). Arder En Deseos: La Concepción De La Fotografía. Barcelona: Gustavo Gili.

Benjamin, W. (2004). Sobre la Fotografía. Valencia: Pre-Textos.

Braun, M. (2014). Memory's Image. Handout con motivo de la muestra Cy Twombly Photographs and Other Works en Art Miami. Miami: James Barron Art LLC.

Brown, S. (2011). Cy Twombly: The Artist's Lexicon in Printmaking. En C. F. Gallery, Cy Twombly Prints. Nueva York, Estados Unidos de América: Craig F. Starr Gallery.

Cullinan, N. (2011). Camera Obscura. En C. L. Avignon, Le Temps Retrouvé, Cy Twombly photographe \& artistes invités (Vol. I). Avignon, Francia: Actes Sud.

de Waal, E. (2012). Cy Twombly, A Kind of Aura. En G. Gallery, Cy Twombly Photographs. Beverly Hills: Gagosian Gallery.

de Waal, E. (2016). A Conversation With Edmund de Waal. En S. Mann, Remembered Light, Cy Twombly in Lexington. New York: Abrams.

Dean, T. (2011). Seven Books Grey (Vols. A Panegyric, Gaeta, Edwin Parker). Viena: MUMOK.

Del Roscio, N. (2014). Cy Twombly Fotografie di Gaeta. Gaeta.

Fitscher, J. (2011). Image Loss. En S. Grosshaus, Cy Twombly Photographien und Druckgraphiken aus der Sammlung Grosshaus. Colonia, Alemania: Buchhandlung Walther Köning.

Geimer, P. (2009). Cy Twombly Painter / Cy Twombly Photographer. En A. H. MUMOK, Cy Twombly States of Mind. Munich: Schirmer / Mosel.

Glozer, L. (2008). Twombly. En C. Twombly, Cy Twombly Photographs 1952-2007. Munich: Schirmer / Mosel.

Gonzalez Flores, L. (2005). Fotografía y Pintura ¿dos medios diferentes? Barcelona: Gustavo Gili.

Greub, T. (2017). Das ungezähmte Bild texte zu Cy Twombly. Alemania: Wilhelm Fink Verlag, ein Imprint der Brill-Gruppe. 
Hochdöfer, A. (2008). Blue goes out, B comes in: Cy Twombly narratives of indeterminacy. En A. H. MUMOK, Cy Twombly States of Mind. Munich: Schirmer / Mosel.

Jacobus, M. (2015). Aura di Limoni (Aura of Lemons). En G. Gallery, Cy Twombly Photorgraphs Volume II. Londres: Gagosian Gallery.

Katz, V. (2002). Cy Twombly's Photographs. En N. Del Roscio, Cy Twombly, photographs 1951-1999. Munich: Schirmer / Mosel.

Katz, W. (1993). Cy Twombly Photographs. En M. M. Gallery, Cy Twombly Photographs. Nueva York: Matthew Marks Gallery New York.

Mann, S. (2015). Hold Still. New York: Little, Brown and Company.

Mann, S. (2016). A conversation with Edmund de Waal. En S. Mann, Remembered Light, Cy Twombly in Lexington. Nueva York: Abrams.

Mann, S. (Miércoles 7 de Octubre de 2016). Artistic Legacy of Cy Twombly. Roma: American Academy in Rome.

Miller, P. B. (2015). Cy Twombly, Photographer. En A. A. Rome, Cy Twombly, Photographer. Poznán: Nero.

Molesworth, H. (2014). Leap Before You Look: Black Mountain College 1933-1957. New Haven: Yale University Press.

Nesin, K.. Cy Twombly: Things. New Haven: Yale University Press.

Rockburne, D. (2011). Moveable Feast. Art Forum, 50(3). Nueva york.

Storsve, J. (ed.) (2016). Cy Twombly. Paris: Centre Pompidou.

Twombly, C. (Agosto-Septiembre de 1957). Documenti di una nuova figurazione: Scialoja, Novelli, Alechinsky, PeriJli, Twombly, I(2). Roma.

Twombly, C. (2000). Entrevista con David Sylvester (Junio 2000). En D. Sylvester, Interviews with American Artists. New Haven y Londres: Yale.

Twombly, C. (2008). History Behind the Thought. En N. Serota, Cy Twombly: Cycles and Seasons. Londres: Tate Publishing.

Twombly, C. (2010). Entrevista con Marie-Laure Bernadac. En M.-L. Bernadac, Cy Twombly The Ceiling un Plafond pour le Louvre. Paris: Musée du Louvre éditions.

v. Amelunxen, H. (2011). Do Not Interrupt this Rose: Light Texts by Cy Twombly. En C. Twombly, Cy Twombly Photographs III 19512011. Munich: Schirmer / Mosel.

v. Amelunxen, H. (2012). Entrevistado por Xavier Flament en Twombly as photographer: a work of light. Visitor's Guide motivo de la exposición CY TWOMBLY Photographs 1951 - 2010. Bruselas: BOZAR.

Varnedoe, K. (2008). El Lepanto de Cy Twombly. En M. d. Prado, Lepanto by Cy Twombly. Madrid: Museo del Prado.

Waters, J. (2010). Role Models. Nueva York: Farrar, Straus and Giroux. 